\title{
Improving the accuracy of multi breath-hold diffusion tensor MRI tractography of the heart using dynamic motioncorrection
}

\author{
Choukri Mekkaoui", Sonia Nielles-Vallespin, Marcel P Jackowski, Peter D Gatehouse, Dudley J Pennell, \\ David N Firmin, David E Sosnovik
}

From 16th Annual SCMR Scientific Sessions

San Francisco, CA, USA. 31 January - 3 February 2013

\section{Background}

Diffusion Tensor MRI (DTI) tractography of the human heart can be performed in vivo, but requires multiple breatholds per slice to achieve adequate SNR [1,2]. The physiological noise inherent to multiple breatholds results in a diffusion-encoded volume in which the data vary as a function of space and time. This may hinder the assessment of diffusion based-indices in the heart and accurate tractography of myofiber architecture. In this study, we investigate the effect of a novel automated motion correction method on in vivo DTI of the heart.

\section{Methods}

DTI of 10 normal volunteers was performed on a 3T clinical scanner (Skyra, Siemens) with the following parameters: 6 diffusion-encoding directions, $b=350 \mathrm{~s} / \mathrm{mm}^{2}$, fat saturation, TR/TE $=1100 / 23 \mathrm{~ms}, \mathrm{BW}=2442 \mathrm{~Hz} /$ pixel, spatial resolution $=2.7 \times 2.7 \times 8 \mathrm{~mm}^{3}, 8$ averages. This required 24 separate breatholds for a 3 -slice diffusion-encoded volume. On a chosen reference frame, $\mathrm{n}$ radial scanlines (Figure 1A) starting at the LV-RV junction and crossing at the center of the LV cavity were defined as the registration axes. Motion was estimated by matching the intensity gradient profiles of corresponding radial scanlines between frames and at all 3 slice levels. A rigid registration described by a set of translations and rotations was then determined between pairs of images, iteratively (Figure 1B). Convergence was achieved upon reaching a global minimum of the quadratic error at each level. The signalnoise-ratio (SNR) was calculated at each pixel $\mathbf{r}$ with a given number of averages (repetitions) $t$, such that $\mathrm{SNR}_{\mathrm{t}}$
$(\mathbf{r})=\operatorname{MEAN}_{\mathrm{t}}(\mathbf{r}) / \mathrm{SD}_{\mathrm{t}}(\mathbf{r})$ [3]. SNR, with and without motion correction, was measured in each voxel at end-diastole and end-systole. Fiber tracking was performed with a $4^{\text {th }}$ order Runge-Kutta approach [4].

\section{Results}

At end-diastole, an increase of $24 \%$ was observed in the SNR of the T2-weighted images, and an average SNR increase of $21 \%$ was seen in the diffusion-weighted images (Figure 1C). At end-systole, a relatively uniform SNR increase of $15 \%$ was seen with motion correction for diffusion-free and diffusion-weighted images. Figure 2 shows tractograms in the lateral wall of the left ventricle at enddiastole and end-systole. Motion correction frequently increased the fiber track lengths, consistent with the observed increase in SNR, and in some cases also rectified their orientation (see endocardial fibers at end-systole, Figure 2B vs. 2D).

\section{Conclusions}

DTI tractography can be performed in vivo over multiple breatholds, but is affected by physiological noise. Here, we show that motion correction over space and time can reduce the noise produced by multiple breatholds while increasing the quality of the resulting tractograms. This approach paves the way for the use of free breathing navigator-based DTI for high-resolution tractography of the heart.

\section{Funding}

R01HL093038. 

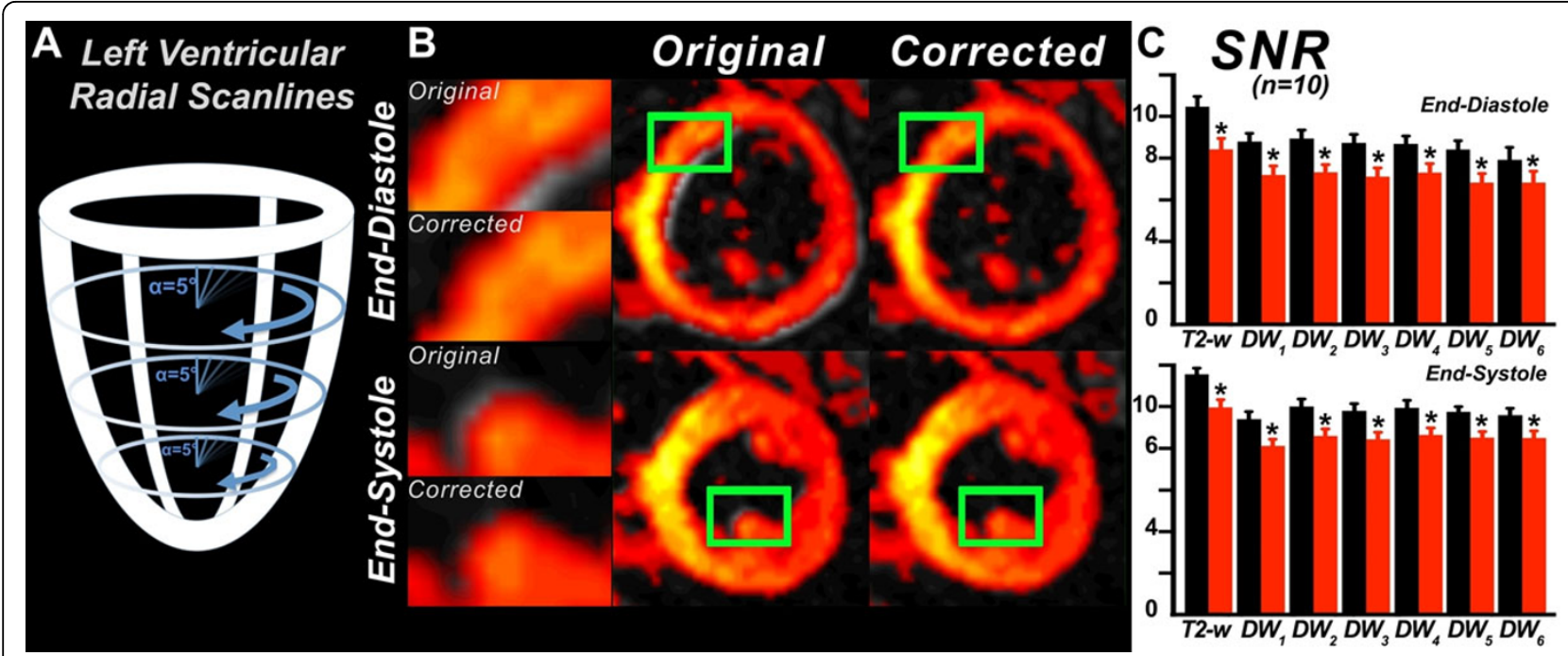

Figure 1 Motion correction of images in a diffusion-encoded 3D volume. (A) The diffusion encoded volume consisted of a slice at the midventricular level, a more basal slice and a more apical slice. Radial scanlines with an angular resolution of 5 degrees were acquired and used for matching frames at each level. (B) Overlay of two short-axis slices, one depicted in grayscale and the other in a hot colormap, before (original) and after motion correction. Alignment of the images and their SNR (C) is significantly improved ( $<<0.01$, Mann-Whitney) by motion correction (black bars $=$ corrected; red bars $=$ original).

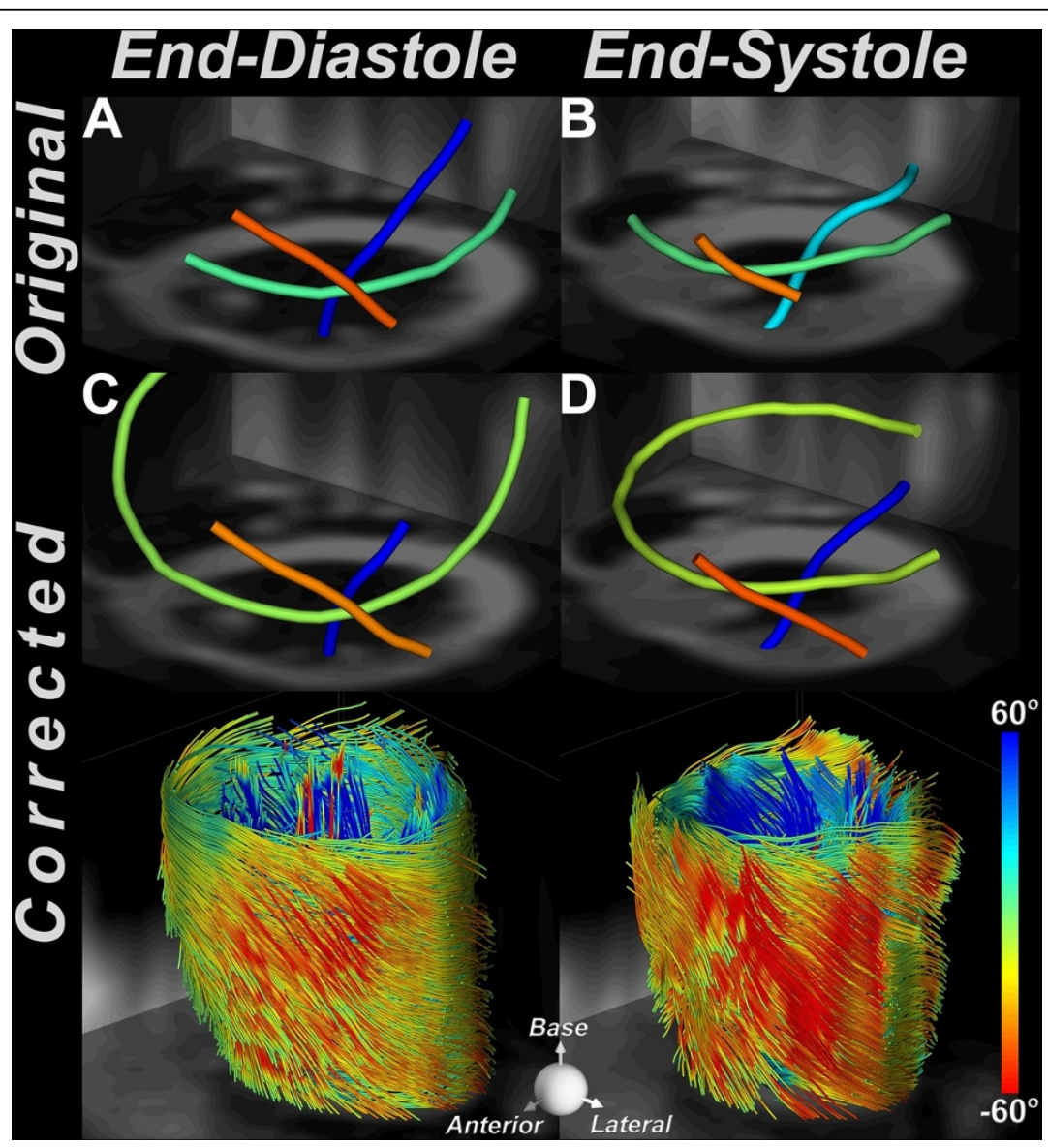

Figure 2 DTI-tractography in vivo with and without motion correction. Motion correction frequently increased the length of the tracked fibers. This can be best appreciated through comparison of the midmyocardial fibers (green-yellow) without motion correction (2A, 2C) and with motion correction (2B, 2D). Motion correction also rectified the orientation of some of the myofibers (endocardial fibers in systole, 2B vs. 2D). 
Published: 30 January 2013

\section{References}

1. Reese TG, et al:. Magn Reson Med 1995.

2. Nielles-Vallespin S, et al:. Magn Reson Med 2012.

3. Reeder SB, et al:. Magn Reson Med 2005.

4. Mekkaoui, et al:. J Cardiovasc Magn Reson 2012.

doi:10.1186/1532-429X-15-S1-081

Cite this article as: Mekkaoui et al.: Improving the accuracy of multi breath-hold diffusion tensor MRI tractography of the heart using dynamic motioncorrection. Journal of Cardiovascular Magnetic Resonance 2013 15(Suppl 1):081.

Submit your next manuscript to BioMed Central and take full advantage of:

- Convenient online submission

- Thorough peer review

- No space constraints or color figure charges

- Immediate publication on acceptance

- Inclusion in PubMed, CAS, Scopus and Google Scholar

- Research which is freely available for redistribution

Submit your manuscript at www.biomedcentral.com/submit
C Biomed Central 